\title{
IDOSOS EM INSTITUIÇÕES DE LONGA PERMANÊNCIA: CONTRIBUIÇÕES ERGONÔMICAS PARA DORMITÓRIOS EM UM ESTUDO DE CASO
}

\author{
ELDERLY IN LONG-STAY INSTITUTIONS: ERGONOMIC \\ CONTRIBUTIONS TO DORMITORIES IN A CASE STUDY
}

\author{
Dayane Guinho de Almeida ${ }^{1}$, Bacharelanda. \\ Bruno Xavier da Silva Barros ${ }^{2}$, M.Sc. \\ (1) universidade Federal de Pernambuco \\ e-mail:dayaneguinho@gmail.com \\ (2) Universidade Federal de Pernambuco \\ e-mail:barros_bruno@hotmail.com
}

Palavras-chave: Idosos, ILPI, ergonomia do ambiente construído.

\begin{abstract}
O processo natural de envelhecimento produz diferentes efeitos nos indivíduos e esta consequente sensibilidade corporal amplia os riscos de doença e as perdas funcionais. Faz-se necessário proporcionar aos usuários idosos condições mínimas para sua independência, segurança e comodidade dentro de um ambiente necessário ao seu cotidiano, notadamente na melhoria da sua qualidade de vida aos idosos institucionalizados, os quais não contam com a presença cotidiana dos familiares. Dentro deste contexto, a corrente pesquisa repousou o foco no desenvolvimento de requisitos projetuais para concepção e adaptação ergonômica do dormitório de uma instituição de longa permanência para idosos. Para tanto, guiamos o estudo através da Metodologia para Projetos de Construção Centrados no Usuário, proposta por Attaianese e Duca (2012), a qual conduziu a sugestão de recomendações que norteiam o processo adaptativo dos dormitórios analisados, focado no conforto e bem-estar dos idosos.
\end{abstract}

Key-words: Elderly, LSIE, ergonomics of the built environment.

The natural aging process produces different effects in humans and this consequent bodily sensitivity magnifies the risks of disease and functional losses. It is necessary to provide to the elderly users minimum conditions for their independence, safety and comfort within an environment necessary for their daily life, especially in the improvement of their quality of life to the institutionalized elderly, who do not rely on the daily presence of their relatives. Within this context, current research focused on the development of design requirements for ergonomic design and adaptation of the dormitory of a long-stay institution for the elderly. To that end, we guided the study through the Methodology for User-Centered Construction Projects proposed by Attaianese and Duca (2012), which led to the suggestion of recommendations that guide the adaptive process of the analyzed dormitories, focused on the comfort and well-being of the elderly. 


\section{$16^{\circ}$ \\ ERGODESIGN USIHC CINAHPA}

$16^{\circ}$ Ergodesign - Congresso Internacional de Ergonomia e Usabilidade de Interfaces Humano Tecnológica: Produto, Informações Ambientes Construídos e Transporte

$16^{\circ}$ USIHC - Congresso Internacional de Ergonomia e Usabilidade de Interfaces Humano Computador

CINAHPA | 2017 - Congresso Internacional de Ambientes Hipermídia para Aprendizagem.

\section{Introdução}

É fundamental considerar os preceitos ergonômicos na hora de planejar os ambientes, os especialistas explicam que boa postura $\mathrm{e}$ regulagens de alturas corretas são itens indispensáveis a serem planejados, lembram que o biótipo de cada pessoa e as características específicas de cada usuário demandam especificações próprias e individualizadas.

Os Estudos apontados segundo Ribas \& Ely (2002), demonstraram que o espaço a considerar deve permitir o acompanhamento das mudanças no corpo humano ocorridas frente ao envelhecimento, a fim de propiciar aos idosos mecanismos que thes garantam mais independência para uma vida normal e igualdade de cidadania e na utilização de edificações, espaços, mobiliários e equipamentos urbanos, apesar das próprias limitações impostas pela velhice, sobretudo aos de menor renda.

As alterações biológicas no processo de envelhecimento são progressivas e irreversíveis; há diminuição da capacidade motora, de equilíbrio e dos reflexos. Essas alterações, no princípio, por volta dos 30 anos, aumentam progressivamente, sem terem algum significado com a incapacidade de um ou mais sistemas do corpo (PEREIRA 2007).

Uma grande quantidade de longevos no Brasil reside permanentemente em Instituições de Longa Permanência para Idosos (ILPI). Nestes abrigos, os idosos desempenham atividades cotidianas tradicionais, as quais demandam níveis de autonomia similares aos de adultos saudáveis. Desta forma, o ambiente institucional necessita ser adequado para atender às principais limitações funcionais do idoso, garantindo-lhe conforto, segurança e independência para a realização de suas atividades diárias, além de intervir através da redução dos impactos dos problemas de saúde que surgem com o passar dos dias, como as quedas, que geram imobilizações, fraturas, medo, dependência e uma série de consequências limitantes para a vida do asilado.
Dentro deste contexto, a corrente pesquisa repousou o olhar sobre a necessidade de prover uma lista de recomendações ergonômicas para o norteamento adaptativo de um dormitório destinado ao idoso em uma instituição de longa permanência. Neste sentido, tornou-se necessário identificar subsídios acerca das limitações naturais decorrentes do processo de envelhecimento; verificar a interação entre o idoso e o ambiente do estudo de caso, em relação a alcances, inclinações, posturas, esforços, atividades desempenhadas e riscos de lesão; identificar situações de risco de lesões causadas pelas atividades diárias e pelas posturas assumidas pelo usuário no ambiente investigado.

A presente pesquisa visou fornecer para o design, recomendações ergonômicas que devem ser levadas em consideração para adaptações e/ou projetos de dormitórios direcionados ao conforto e bem-estar dos idosos. Para tanto, lançou-se mão da Metodologia para Projetos de Construção Centrados no Usuário, proposta por Attaianese e Duca (2012), a qual conduziu o estudo ao alcance dos resultados.

A investigação selecionou os dormitórios de uma Instituição de Longa Permanência para Idosos situada em um município do agreste pernambucano, a qual conta com doações e apoio governamental para manter sua estrutura física.

\section{Fundamentação teórica}

\subsection{O processo de envelhecimento e suas sequelas}

Causador de alterações no funcionamento do organismo, o envelhecimento pode ser analisado como processo gradual do organismo, no qual o indivíduo tem dificuldades, em maioria dos casos, de se adaptar ao meio ambiente tornando-se mais vulnerável às doenças (PEREIRA, 2007).

O envelhecimento humano pode ser entendido pela influência causada por alguns fatores, tais como classe social, gênero, padrões de saúde individuais

\section{Realização:

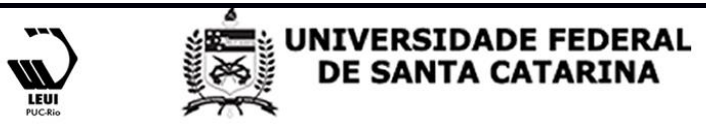




\section{$16^{\circ}$ \\ ERGODESIGN USIHC CINAHPA}

$16^{\circ}$ Ergodesign - Congresso Internacional de Ergonomia e Usabilidade de Interfaces Humano Tecnológica: Produto, Informações Ambientes Construídos e Transporte

$16^{\circ}$ USIHC - Congresso Internacional de Ergonomia e Usabilidade de Interfaces Humano Computador

CINAHPA | 2017 - Congresso Internacional de Ambientes Hipermídia para Aprendizagem.

e coletivos, e a própria cultura. Costa e Pereira (2005) afirmam que as mudanças e perdas fazem parte do envelhecimento, e que a estatura do indivíduo a partir dos 40 anos diminui cerca de um centímetro por década, devido à redução de massa óssea e alterações degenerativas da coluna vertebral; a pele fica mais fina, menos elástica e com menos oleosidade; a visão também sofre modificações, há um declínio e geralmente piora para objetos mais próximos; a audição diminui as funções mentais e permanecem preservadas até o final da vida apesar do peso e do volume do encéfalo diminuir por perda de neurônios, justamente por causa desta redução.

A diminuição auditiva é apontada por (Saldanha e Caldas, 2004, p.204) como o déficit sensorial mais prevalente representando cerca de $30 \%$ das pessoas com mais de 65 anos, a redução de prazer proporcionado por alimentos são influenciados consideravelmente através do paladar e olfato que influencia diretamente a qualidade de vida desses usuários, e ainda parte do sistema sensorial quem compõem o sistema proprioceptivo cuja representação ocorre através do tato afim de transmitir informações, a visão e o sistema vestibular, que é responsável pelo equilíbrio do ouvido, ambos possuem uma ligação com o equilíbrio postural pela transmissão ao cérebro realizada por ambos quanto as relações e percepções corporais. Os autores complementam afirmando que algumas consequências são observadas na visão do usuário, a diminuição de capacidade acomodativa, bem como a sensibilidade ao contraste no ajuste entre os níveis de iluminação, a menor adaptação ao escuro e o prejuízo na discriminação de cores.

Ocorrem também alterações musculoesqueléticas e ósseas, segundo Esquenazi et al. (2013), depois dos 35 anos, mudanças na cartilagem articular, as quais provocam, junto com alterações

biomecânicas possivelmente adquiridas, diversas degenerações que podem acarretar num declínio na capacidade de locomoção e flexibilidade, aumentando assim o risco de lesões. Fatores como obesidade e hereditariedade também podem contribuir com o aparecimento de problemas ligados a essas alterações.

\subsection{Idosos e Instituições de Longa Permanência}

O cuidado com as pessoas idosas, segundo a legislação brasileira é dever da família e da comunidade, os idosos sem rede familiar de apoio em situação de vulnerabilidade são recebidos nessas instituições do tipo asilar. O ministério do Desenvolvimento social oferece serviços em áreas social, psicológica, médica, de fisioterapia, de terapia ocupacional e demais atividades específicas para o segmento social. (MDS - Programa de atenção à pessoa idosa).

As Instituições de Longa Permanência para Idosos (ILPI) são conhecidas popularmente por asilos, do grego asylon, cujo significado é local onde as pessoas sentem-se abrigadas e protegidas contra danos de qualquer natureza. O seu surgimento foi fundamentado na caridade em ter onde se alimentar, se banhar e dormir; num atendimento básico às necessidades de vida, destinadas ao amparo aos "sem família, pobres e mentalmente enfermos. A manifestação inicial estava relacionada à caridade, em uma perspectiva assistencialista determinando a homogeneidade da velhice, e a percepção dela como degeneração e decadência e a infantilização do idoso" (CREUTZBERG; GONÇALVES; SOBBOTKA, 2008).

As ILPIs são apontadas pela Vigilância Sanitária no Estado de São Paulo como equipamento social, segundo consta a Resolução SS123/2001 que define e classifica as instituições geriátricas no âmbito do Estado, porém diferencia a ILPI de Casa de Repouso, isso porque elas são destinadas centralmente à prestação dos serviços de assistência médica em regime de assistência asilar. A Classificação Nacional de Atividade Econômica (CNAE), instrumento de padronização nacional dos códigos de atividade econômica e dos critérios de enquadramento utilizados pelos diversos órgãos da Administração Tributária do país, também faz 
$16^{\circ}$ Ergodesign - Congresso Internacional de Ergonomia e Usabilidade de Interfaces Humano Tecnológica: Produto, Informações Ambientes Construídos e Transporte

$16^{\circ}$ USIHC - Congresso Internacional de Ergonomia e Usabilidade de Interfaces Humano Computador

CINAHPA | 2017 - Congresso Internacional de Ambientes Hipermídia para Aprendizagem.

essa distinção das instituições destinadas ao cuidado a pessoas idosas sendo o abrigo de idosos como sendo os asilos, casas para velhice com alojamento, ILPI ou residências protegidas sendo destinadas à assistência social de idosos em regime de internato quando o elemento central desse atendimento não constitui tratamento médico, já as clinicas e residências geriátricas são as casas de repouso para pacientes em internato com mais de 60 anos, sob orientação médica, com prestação de serviços de enfermagem e de apoio terapêutico (WATANABE \& GIOVANNI, 2009).

As instituições de longa permanência para idosos segundo Brito e Ramos (2002), são uma opção de cuidados para pessoas muito dependentes e frágeis, ou por razões médico-sociais que não podem ficar em suas residências. O número de idosos institucionalizados é maior entre as mulheres e aumentou entre as idades mais avançadas, o cuidado à saúde dos idosos residentes se faz necessário pois o número de idosos que apresentam algum tipo de deficiência física ou mental é muito mais alto entre os institucionalizados do que nos demais idosos (CAMARANO, 2005). Born e Boechat (2002) definem a ILPI como um serviço de assistência de natureza médico-social e sócio sanitária, onde se proporciona cuidados, um lugar para se viver com dignidade. Os cuidados devem ser abrangentes a vida social, emocional, as necessidades de vida diária e assistenciais à saúde, sendo caracterizado como um serviço híbrido, de caráter social e de saúde.

Os motivos dos idosos serem institucionalizados geralmente estão relacionados ao caráter socioeconômico, tais como a ausência do suporte familiar ou social e precariedade de condições financeiras; às condições de saúde, tido sequelas de doenças crônicas, limitações físicas e cognitivas, importantes para o desenvolvimento das atividades do cotidiano e necessidade de reabilitação após período de internação hospitalar; e também por opção pessoal (PAVARINI , 1996; BOECHAT, 1996; CHAIMOWICZ e GRECO, 1999; CALDAS, 2003; CORTELLETI, 2004).
Os dormitórios das instituições de longa permanência podem apresentar variações quanto as suas configurações. De acordo com a Resolução da Diretoria Colegiada (RDC) n ${ }^{\circ} 283$ são feitas exigências tipo, separação dos quartos por sexos diferentes, a quantidade de idosos sendo 4 por quarto e dotados de banheiro.

\subsection{O ser humano no ambiente construído}

A Ergonomia ambiental ou Ergonomia do ambiente construído possui métodos de análise que se fundamentam na compreensão de atividades reais em situações do trabalho, e quando analisada sob enfoque, a Ergonomia acerca da condição adequável ou quanto a identificação de um ambiente para o usuário relacionado as tarefas a desenvolver-se, tende a envolver algumas variáveis, que são resultantes de uma tarefa de adequação demasiadamente complexa.

A Ergonomia do ambiente construído é considerada a vertente do campo da Ergonomia cuja preocupação é com o estudo do ambiente físico, no qual é analisado relacionando as questões do uso de espaços com adequação aos usuários (PAIVA 2012). O segmento é guiado pelos métodos de análise que compreendem a realização das atividades em situações reais de trabalho, tendo o contexto considerado através da diversidade dos indivíduos participantes.

Segundo Mont'Alvão e Villarouco (2011, p. 31), a Ergonomia do Ambiente Construído deve considerar os elementos que compõem o ambiente, que são os referentes ao conforto do ambiente (térmico, lumínico e acústico), quanto a percepção do ambiente (aspectos cognitivos), quanto as adequações (revestimentos e acabamentos), também quanto as cores e texturas, assim como acessibilidade, interligadas as medidas antropométricas (layout e dimensionamento), sem esquecer da sustentabilidade.

As perdas consequentes do processo de envelhecimento impõem dificuldades no desempenho de atividades, mesmo que sejam rotineiras ao idoso, sendo assim, o ambiente físico

\section{Realização: "-) UNIVERSIDADE FEDERAL


$16^{\circ}$ Ergodesign - Congresso Internacional de Ergonomia e Usabilidade de Interfaces Humano Tecnológica: Produto, Informações Ambientes Construídos e Transporte

$16^{\circ}$ USIHC - Congresso Internacional de Ergonomia e Usabilidade de Interfaces Humano Computador

CINAHPA | 2017 - Congresso Internacional de Ambientes Hipermídia para Aprendizagem.

construído deve atender o princípio da Ergonomia, estando em consonância com o usuário a fim de gerar autonomia, segurança e maior conforto. Assim sendo, o ambiente construído assume para os idosos uma dimensão importante no processo de envelhecimento, impelindo as limitações, interferindo diretamente em sua independência influenciando na capacidade funcional assim como no comportamento. Percebe-se desse modo que as limitações físicas dos idosos devem ser consideradas pelo o espaço físico, a fim de propor as melhorias na qualidade de vida, autonomia em atividades cotidianas assim como a promoção de independência, intervindo na redução ao risco de acidentes (FLORES, 2008).

\section{Procedimentos Metodológicos Adotados}

Para a condução do estudo, guiamo-nos pela Metodologia para Projetos de Construção Centrados no Usuário, proposta por Attaianese e Duca (2012). Foram contempladas as quatro primeiras etapas desta metodologia, a saber: Briefing de Design; Perfis do Usuário e Grupos de Ajuste; Análise da Tarefa; e Adaptação às necessidades do Usuário.

A etapa definida pela coleta das informações acerca do ambiente é denominada Briefing de Design, nela foi exposta a composição do ambiente assim como a realização do detalhamento minucioso para a composição da pesquisa. Os dados obtidos nessa fase serão coletados a partir da realização de entrevistas, apresentadas por questionários, feitas aos usuários relacionados ao processo, neste caso serão aplicados a funcionárias e primordialmente aos usuários institucionalizados condicionados ao tipo de dormitório analisado, onde com o uso de um aparelho portátil será possível realizar gravações, ambas concretizadas no próprio local de estudo. Para a coleta de imagens se faz necessário o uso de uma câmera fotográfica.

A partir da realização de investigação se tornará possível constatar os Perfis de Usuários e Grupos de Ajuste envolvidos, estes se dividem entre diretos e indiretos, sendo os usuários diretos o principal a executar as atividades e o que executa a ação frequentemente; por outro lado, também foram citados informações acerca dos usuários que estão envolvidos ao ambiente e executam algumas atividades eventualmente.

Na etapa de Análise da Tarefa foram apresentadas as atividades realizadas pelas usuárias envolvidas da pesquisa, nela foi apontada a rotina através da exposição das imagens, contendo as considerações acerca das posturas rotineiras dos usuários envolvidos na investigação. A partir da apresentação explicativa das posturas se tornou possível apontar os problemas encontrados de acordo com a Ergonomia, justificando a causa das tensões e má posturas. Em adição a esta fase, investigou-se o conforto ambiental do dormitório (parâmetros de iluminação, ruído e temperatura) e $\mathrm{o}$ aspectos antropométricos envolvidos.

A etapa de Adaptação às Necessidades dos Usuários é caracterizada pela da síntese de dados, nesta fase foram apontados os problemas possivelmente encontrados, assimilando as adaptações necessárias ao projeto, contemplando as correções apontadas, para que pudessem ser feitas as recomendações ergonômicas do ambiente para o projeto centrado no ser humano.

\subsection{Apresentação do local do Estudo de Caso}

A Instituição de Longa Permanência selecionada para o estudo de caso é uma instituição filantrópica, iniciou seus trabalhos acolhendo pobres e mendigos ou pessoas carentes, à princípio com atendimento centrado aos moradores de rua. Fundada em 3 de março de 1948, por haver uma demanda de idosos carentes cuja quantidade superou o previsto, foi caracterizada como Instituição de Longa Permanência para Idosos, conforme preconiza a lei 10.741/2003 (Estatuto do Idoso) e outras legislações relacionadas (figura 1).

\section{Realização:}




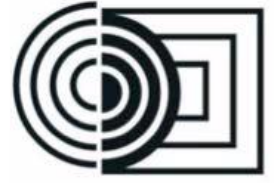

ERGODESIGN USIHC CINAHPA

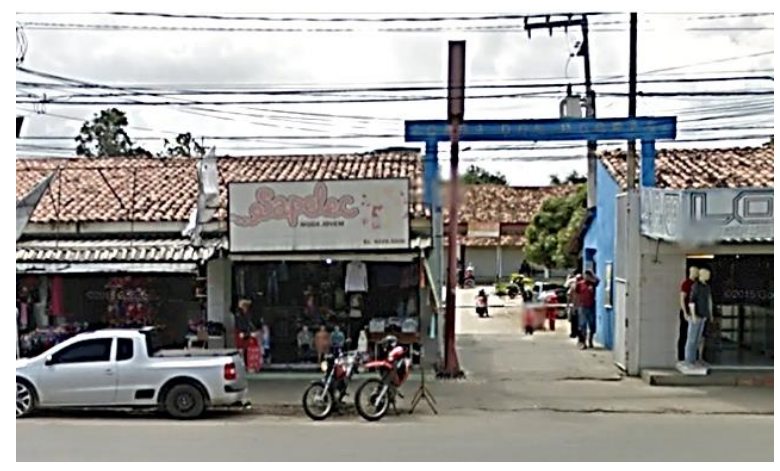

Figura 1: Portal de entrada da ILPI. Fonte: Google Earth.

A ILPI atende, no momento de realização do estudo, 88 residentes, os quais estão divididos entre 42 homens e 46 mulheres, não possui fins lucrativos e mantém-se de doações da maçonaria e da comunidade em geral, por intermédio de campanhas, donativos do comércio e indústria, de renda proveniente dos idosos que recebem algum tipo de benefício ou aposentadoria, de eventos anuais proporcionais, também de alugueis de pontos comerciais localizados na parte externa da instituição, assim como o lucro de estacionamento da área interna.

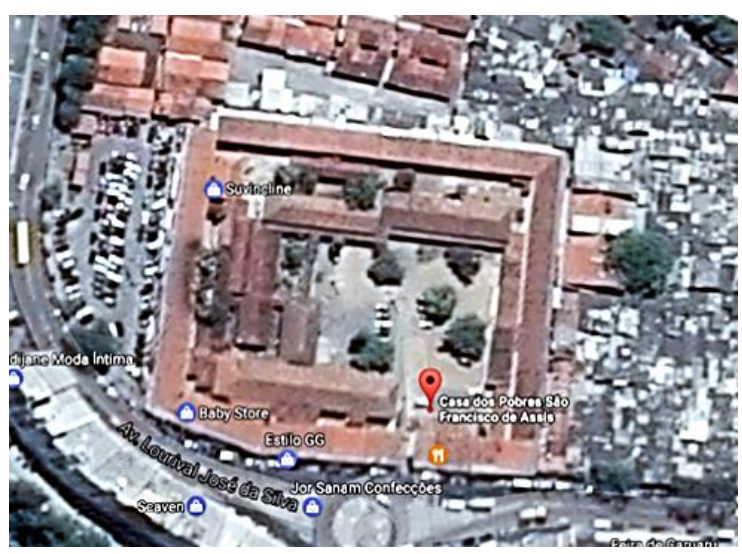

Figura 2: Vista aérea da ILPI. Fonte: Google Earth.

Conta atualmente com 54 funcionários, dentre eles médicos geriátricos, enfermeiros, técnicos em enfermagem, 3 fisioterapeutas, 1 nutricionista, 1 assistente social, 1 terapeuta ocupacional, 2 porteiros, 1 motorista, 2 lavandeiras, 2 cozinheiras e 6 auxiliares de cozinha. $16^{\circ}$ Ergodesign - Congresso Internacional de Ergonomia e Usabilidade de Interfaces Humano Tecnológica: Produto, Informações Ambientes Construídos e Transporte

$16^{\circ}$ USIHC - Congresso Internacional de Ergonomia e Usabilidade de Interfaces Humano Computador

CINAHPA | 2017 - Congresso Internacional de Ambientes Hipermídia para Aprendizagem.
O local funciona 24 horas por dia, porém aberto ao público apenas entre as $11 \mathrm{~h} 00$ e $15 \mathrm{~h} 00$, de domingo a domingo. Possui a capacidade de atender 110 idosos, a idade mínima estipulada para o internamento é de 60 anos, não possui exigências quanto a idade máxima.

\section{Resultados obtidos}

\subsection{Briefing de Design}

Através da investigação feita no campo de estudo, foi constatado a partir das entrevistas feitas com as usuárias da Instituição, que as mesmas apontam necessitar de cuidados específicos quanto a sua mobilidade, foi observado no decorrer a necessidade de um espaço maior para circulação dentro do ambiente, essa foi uma queixa feita especificamente pela usuária indireta para a realização da limpeza. A temperatura foi outro agravante denunciado pelas entrevistadas, o local é apontado como pouco ventilado. Outra verificação que foi feita é quanto ao banheiro que não se encontra no mesmo recinto, e isso faz com que as residentes dos dormitórios tenham que se locomover ao local do banheiro, mesmo que sendo próximo, isso dificulta quando for necessário o uso. Cada usuário institucionalizado possui um armário para armazenamento de objetos de uso, disposto na parede geralmente fixados próximos as camas, é preciso verificar se os armários respeitam as medidas antropométricas das usuárias em

\section{Realização:}




\section{$16^{\circ}$ \\ ERGODESIGN USIHC CINAHPA}

$16^{\circ}$ Ergodesign - Congresso Internacional de Ergonomia e Usabilidade de Interfaces Humano Tecnológica: Produto, Informações Ambientes Construídos e Transporte

$16^{\circ}$ USIHC - Congresso Internacional de Ergonomia e Usabilidade de Interfaces Humano Computador

CINAHPA | 2017 - Congresso Internacional de Ambientes Hipermídia para Aprendizagem.

destino.

O dormitório essencial para o usuário idoso institucionalizado demanda alguns aspectos específicos para sua necessidade, tais como amplitude no espaço e circulação adequada, isso porque existe a necessidade do mesmo de se locomover dentro do ambiente, e também necessita de alguns mobiliários que lhe permita autonomia em suas atividades. A escolha das cores para o ambiente é de extrema importância, pois, é a partir da cor que se possibilita a transmissão de sensações aos usuários. Uma verificação importante a citar também, é quanto ao piso, este sem dúvidas é um dos grandes fatores propensos a quedas, e por isso devem ser escolhidos de forma coerente para que se possa oferecer segurança.

\subsection{Perfis de Usuário e Grupos de Ajuste}

Tomou-se como base um dos dormitórios (cientes de que todos os dormitórios possuem a mesma dimensão, leiaute e os mesmo modelos de móveis). A partir de então entrevistamos as duas usuárias deste dormitório (usuárias diretas) cujas estaturas são de $1,42 \mathrm{~m}$ e $1,45 \mathrm{~m}$, consideradas (baixa estatura) e idades de 78 e 88 anos respectivamente. Aparentemente as longevas são bem cuidadas, com cabelos brancos, unhas limpas, usando roupas leves e geralmente fazem uso de acessórios de beleza, tais como relógio, pulseiras assim como a identificadora do local e também de brincos, e permanentemente encontra-se calçada com sandália de dedo de borracha.

Algumas são dependentes de medicamentos, algumas, em sua grande maioria são acometidas por hipertensão arterial (pressão alta), e ainda uma das usuárias pesquisadas queixa-se de bursite, fatores esses que a limita, impossibilitando-a de realizar algumas atividades e a impede levantar o braço direito por completo.

\subsection{Análise da Tarefa}

A fase de Análise da Tarefa revelou diversos problemas. Inicialmente percebeu-se que ato de levantar-se da cama sem que haja a necessidade de

ajuda de terceiros, em se tratando das idosas, exige bastante esforço. Durante a ação de levantar, a usuária apoia-se na própria cama (colchão) e não existe qualquer haste ou barra de apoio para tal atividade.

O dormitório possui um armário suspenso de duas portas fixado a uma altura superior à estatura das usuárias, prejudicando o acesso aos artefatos pessoais guardados dentro do mesmo. $\mathrm{O}$ acesso dificultado se intensifica ainda mais devido ao fato das portas do armário não possuírem puxadores. Para abertura das portas, as usuárias elevam o membro superior acima do nível da cabeça e tateiam o vértice inferior da porta, a fim de conseguir (através de um manejo fino com as pontas dos dedos e do uso de força) ter acesso à parte interna do móvel. Este tipo de acesso se torna ainda mais comprometido quando as usuárias precisam alcançar artefatos dispostos acima deste móvel suspenso (hábito que só se faz necessário porque a capacidade interna do móvel não é suficiente para comportar todos os utensílios das usuárias) (figura 4).

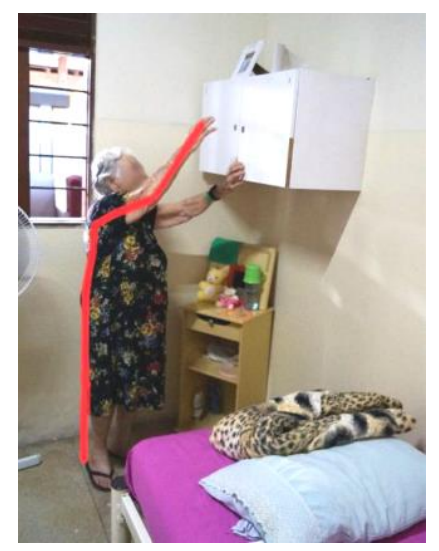

Figura 4: Acesso ao armário suspenso. Fonte: Capturado pelos autores para a pesquisa.

Outro ponto de inadequação observado refere-se à circulação interna do dormitório, a qual revelou obstáculo (ventilador de coluna) e espaço reduzido (Figura 5). 


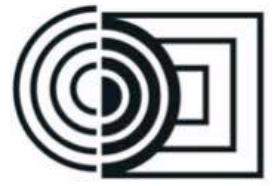
CINAHPA
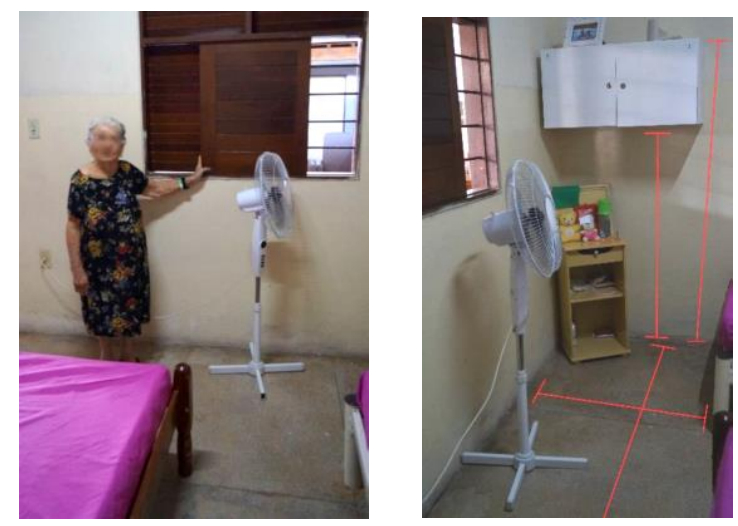

Figura 5 A e B: Reduzido espaço para circulação. Fonte: Capturado pelos autores para a pesquisa.

O quarto apresenta apenas 1 interruptor para acendimento da única lâmpada do dormitório (disposta no centro do teto), o qual fica localizado próximo à porta de entrada do cômodo. Desta forma, durante à noite, as usuárias apagam a lâmpada e caminham arriscadamente até a cama no total escuro. Outro ponto adicional de desconforto é a altura do interruptor, localizado a $1,27 \mathrm{~m}$ do piso, implica na elevação do membro superior das usuárias acima da altura do ombro.

A entrada e saída do dormitório também requerem cuidados, principalmente por haver um desnível de $8 \mathrm{~cm}$ na soleira da porta. Este processo oferece riscos de queda a idosa, intensificada também pelo piso, que não é antiderrapante (nem fora nem dentro do quarto). Essa atividade exige da usuária o esforço ao abrir a porta (cuja maçaneta está disposta acima do nível do ombro da idosa), descer o batente e fechar a porta.

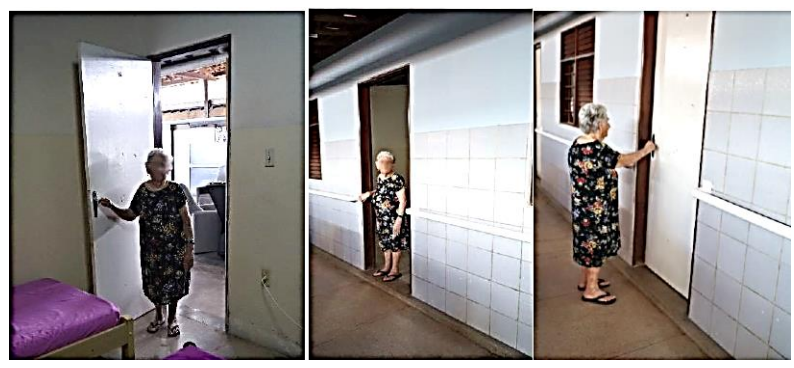

Figura 6 A, B e C: Dificuldades na entrada e saída do cômodo. Fonte: Capturado pelos autores para a pesquisa. $16^{\circ}$ Ergodesign - Congresso Internacional de Ergonomia e Usabilidade de Interfaces Humano Tecnológica: Produto, Informações Ambientes Construídos e Transporte

$16^{\circ}$ USIHC - Congresso Internacional de Ergonomia e Usabilidade de Interfaces Humano Computador

CINAHPA | 2017 - Congresso Internacional de Ambientes Hipermídia para Aprendizagem.

A atividade de entrada e saída é rotineira, principalmente por ser o trajeto que a leva ao banheiro (os dormitórios da instituição não são do tipo suíte), assim como os demais locais da Instituição, sendo por consequência muito realizada.

As cores do ambiente são frias (braço e bege), a escolha se dá pela representação perceptiva que elas transmitem, são consideradas relaxantes, porém a monocromia pode gerar ou agravar a depressão.

Em adição às observações realizadas, buscamos complementar a investigação com uma verificação dos níveis de conforto ambiental. A verificação da temperatura, baseada no clima regional, foi medida em três momentos do dia, às $9 \mathrm{~h} 00$ da manhã $\left(29^{\circ} \mathrm{C}\right)$, já às $14 \mathrm{~h} 20$ foi verificado $\left(32^{\circ} \mathrm{C}\right)$ e às $16 \mathrm{~h} 15$ a temperatura encontrada foi de $\left(31^{\circ} \mathrm{C}\right)$. Deste modo constatou-se uma inadequação relacionada à temperatura indicada pela NBR 16401-2:2008, que recomenda o valor entre $22,5^{\circ} \mathrm{e}$ $25,5^{\circ}$. É válido salientar que pessoas idosas são mais sensíveis a baixas temperaturas, contudo, a disparidade térmica foi bastante alta, o que, reforçados pelo depoimentos das usuárias, nos fez inferir uma inadequação.

Os parâmetros de ruído também foram verificados e foram aferidos três vezes em um dia, em horários alternados, verificou-se que às $9 \mathrm{~h}$ valor mínimo $34 \mathrm{db}$ e máximo de $42 \mathrm{db}$, às 14:21h houve uma pequena variação sendo mínima de $32 \mathrm{db}$ e máxima de $38 \mathrm{db}$, e ás $16: 22 \mathrm{~h}$ os valores encontrados foram de 34db mínimo e $37 \mathrm{db}$ máximo. As disposições da NBR 10151 e demais normas ABNT correspondem aos valores entre 35-45db. Esse cotejamento confirma que o ambiente investigado se encontra adequado.

Os índices de iluminamento foram verificados em três horários distintos do dia, ambos com a lâmpada acesa (recurso constantemente utilizado pelas usuárias). Às $9 \mathrm{~h} 11$ registou-se o valor de 60lux, às $13 \mathrm{~h} 50$ verificou-se $301 u x$ e às $16 \mathrm{~h} 50$ alcançou 40lux. De acordo com a ABNT os valores considerados normais devem estar entre 100-150- 


\section{$16^{\circ}$ \\ ERGODESIGN USIHC CINAHPA}

$16^{\circ}$ Ergodesign - Congresso Internacional de Ergonomia e Usabilidade de Interfaces Humano Tecnológica: Produto, Informações Ambientes Construídos e Transporte

$16^{\circ}$ USIHC - Congresso Internacional de Ergonomia e Usabilidade de Interfaces Humano Computador

CINAHPA | 2017 - Congresso Internacional de Ambientes Hipermídia para Aprendizagem.

200 lux. Dessa forma, os valores de iluminação encontrados no ambiente estão abaixo da média recomendada pelas normas. Esta disparidade pode ser ainda mais grave se considerarmos a atividade de leitura (bíblia) realizada pelas longevas, a qual demanda o valor entre 300 e 500 lux.

A execução das análises tornou visível a necessidade de uma verificação das dimensões internas oferecidas pelo dormitório. Desta forma, consideramos os aspectos antropométricos na visualização das inadequações. à luz dos valores recomendados por Panero e Zelnik (2013) constatou-se que as medidas das camas, apesar das variações, atendem as especificações estabelecidas, enquadram-se entre $91,4 \mathrm{~cm}$ à $99,1 \mathrm{~cm}$, medidas recomendadas pelos autores. Quanto à zona de circulação, os autores recomendam uma distância mínima de $91,40 \mathrm{~cm}$ entre duas camas de solteiro, porém, foi constatado que a medida se encontra desconforme, pois o apresentado foi de $55 \mathrm{~cm}$ de distância máxima encontrada entre as camas do dormitório, o que tende a prejudicar o usuário por não propiciar um acesso confortável. Outro flagrante foi o espaço encontrado entre a lateral da cama e a parede paralela, que consequentemente não atende as recomendações dos autores, que aconselham a distância de $50 \mathrm{~cm}$, o valor encontrado foi de $10 \mathrm{~cm}$.

Por fim, também se verificou que a altura da parte superior do armário suspenso não está acessível ao alcance manual recomendado.

\subsection{Adaptação às Necessidades do Usuários}

A partir da coleta de dados obtidos no estudo realizado nessa pesquisa, foram consideradas entrevistas realizadas e as imagens coletadas, para se obter informações a respeito de problemas posturais, decorrentes de posições incorretas.

Ao se tratar do espaço de circulação, foi verificado que o espaço entre as camas está indevido isso intervém no acesso assim como influência no momento de limpeza do ambiente. A presença do ventilador no corredor de acesso também interfere na circulação, pois, além de diminuir pode ocasionar quedas pela sua base.

Em se tratando de alturas, o mobiliário contido no ambiente investigado, embora o espaço seja consideravelmente pequeno, poucos são encontrados e estão distribuídos de forma regular, as camas por si ocupam a maior parte do ambiente, a presença dos armários fixados nas paredes não interfere na circulação, porém a altura dos mesmos não condiz com o espaço do envelope de alcance das internas. Na parte superior existem pontos altos dificultando o acesso, que além de requer mais esforços afim de alcança-los, também pode ocasionar mais adiante, desconforto articular na região do ombro e complicações na coluna cervical. Em alguns pontos torna-se impossível ter acesso pela altura. Em móveis cujas prateleiras são muito baixas, também são inviáveis, consideradas impossível de alcançar. Outro agravante está no teto que não possui revestimento, além de ser propenso ao acumulo de poeiras, transmite calor, gerando desconforto ao ambiente assim como interfere na limpeza do mesmo, e, requer esforços quando for preciso limpar.

Um fato a ser observado sobre os armários suspensos contidos no local, não possuem puxadores, o que dificulta a abertura e consequentemente o fechar deles. Outra inconformidade, foi quanto a forma e as formas do armário suspenso, pois possui quinas vivas, as quais podem lesionar a cabeça das usuárias.

A fim de atender essa necessidade no dormitório, a usuária faz o uso de um ventilador de pé, porém, o problema encontrado na sua existência está encontrado em sua posição, o mesmo encontra-se localizado de forma irregular na área de circulação entre a porta e os armários, ocupando um espaço consideravelmente grande e fica bem próximo a janela, a única responsável pela ventilação e iluminação natural do ambiente. A base do equipamento em formato de x pode causar quedas. Outro agravante é a fiação do mesmo que se encontra exposta.

A avaliação acerca da iluminação do ambiente permitiu constatar-se inadequada, as 
$16^{\circ}$ Ergodesign - Congresso Internacional de Ergonomia e Usabilidade de Interfaces Humano Tecnológica: Produto, Informações Ambientes Construídos e Transporte

$16^{\circ}$ USIHC - Congresso Internacional de Ergonomia e Usabilidade de Interfaces Humano Computador

CINAHPA | 2017 - Congresso Internacional de Ambientes Hipermídia para Aprendizagem. irregularidades foram representadas pelo baixo índice de luminosidade verificada a partir das medições realizadas. Os índices de temperatura também se mostraram em desconformidade, prejudicando o alcance de um conforto térmico.

A finalização das etapas investigativas, aliadas ao resgate de toda a problemática acerca da convivência cotidiana dos idosos no dormitório da ILPI analisada, tornou possível a proposição de recomendações ergonômicas de adequação do espaço com foco no ser humano, dispostas na tabela a seguir:

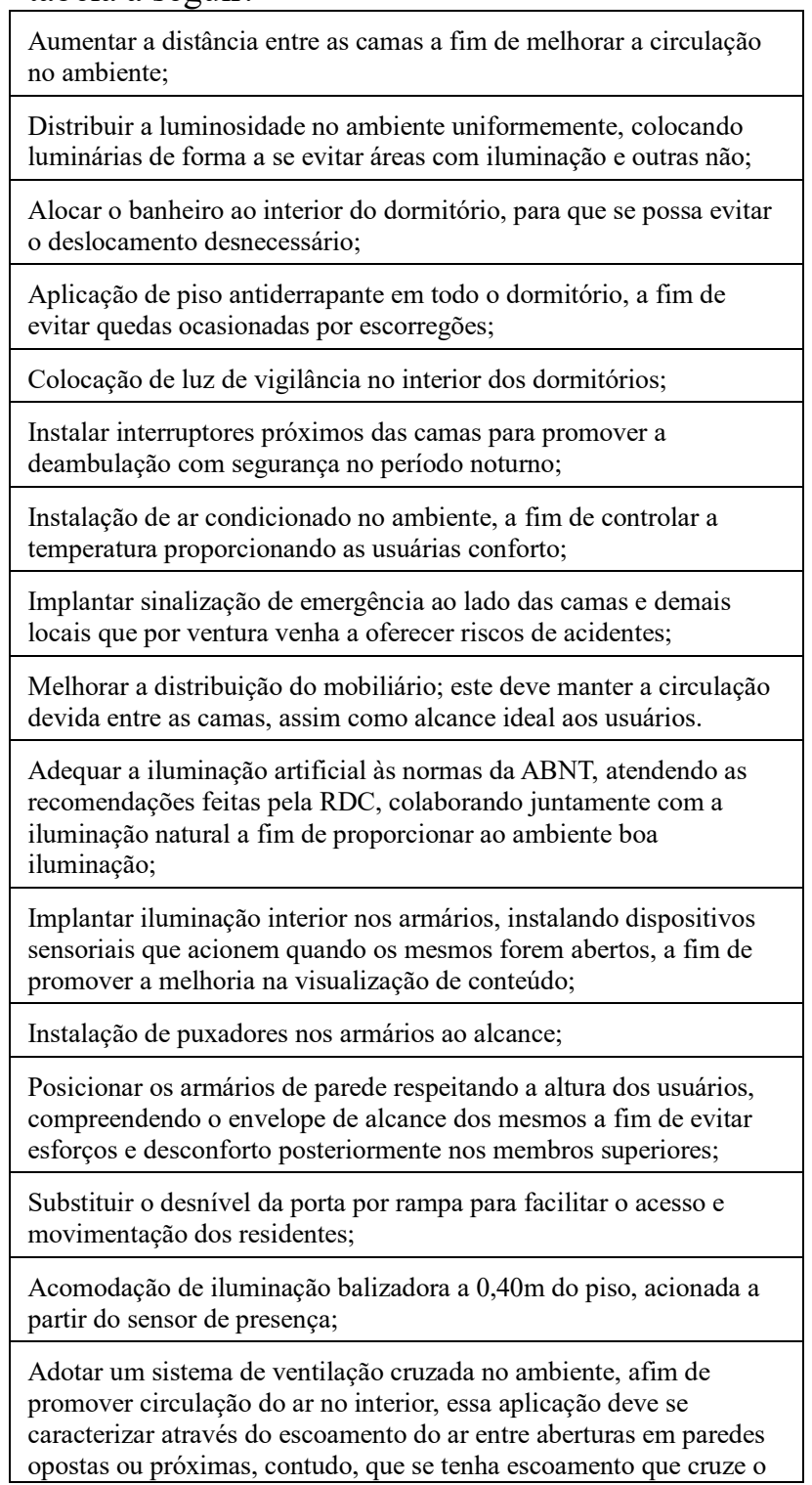

ar no ambiente de forma diagonal.

Aplicar cores que permita transmitir sensação aceitável de conforto aos usuários residentes em Instituições de Longa Permanência, tais como azul e verde, a fim de promover a sensação de conforto e agradabilidade, podendo mesclar com pequenas quantidades dos tons de laranja, ou amarelo, a fim de transmitir entusiasmo e alegria ao dormitório contrastando com as demais cores.

Incrementar ao ambiente uma ventilação que proporcione a melhor circulação do ar, o recomendável é a ventilação cruzada, pois ela permite refrescar o ambiente de forma mais natural, principalmente nos dias de calor intenso.

Tabela 1: Recomendações ergonômicas.

\section{Conclusões}

Com a realização das análises foi possível perceber que, embora o dormitório seja o ambiente mais cômodo aos idosos (a tendência é de se passar maior tempo), o ambiente é apontado como grandes ocorrências de desconfortos e quedas segundo as pesquisas e depoimentos dos usuários. Tendo isso em vista, verifica-se a importância de ser estudado com atenção, com respaldo técnico/profissional, perceptivos e emocionais, buscando a garantia de segurança e conforto aos usuários idosos, tomando os cuidados devidos e que as adaptações realizadas no ambiente não causem frustrações e nem causem prostração ou incapacidade.

As recomendações aqui exemplificadas poderão ser aplicadas em ambientes internos de dormitórios em geral, embora em sua maior proeminência tenha sido para Instituições de Longa Permanência para Idosos, também permite sua aplicação em dormitórios em geral para idosos. A importância de sua aplicação se dá pela preocupação em tornar mais prazerosa a vida dos usuários idosos, a Ergonomia pode tornar os recintos igualmente humanizados e funcionais, além de considerar as limitações e capacidades dos usuários, distanciando modelos existentes apreciando as subjetividades dos próprios. Os elementos gerados com o estudo podem ser utilizados para adaptação ou concepção de projetos direcionados a este tipo de público alvo.

As pesquisas em Ergonomia voltadas para o estudo
Realização:

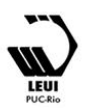

\section{UNIVERSIDADE FEDERAL} DE SANTA CATARINA
INSTITUTO FEDERAL

Santa Catarina

Câmpus Palhoça Bilíngue 
$16^{\circ}$ Ergodesign - Congresso Internacional de Ergonomia e Usabilidade de Interfaces Humano Tecnológica: Produto, Informações Ambientes Construídos e Transporte

$16^{\circ}$ USIHC - Congresso Internacional de Ergonomia e Usabilidade de Interfaces Humano Computador

CINAHPA | 2017 - Congresso Internacional de Ambientes Hipermídia para Aprendizagem.

das relações entre o ambiente e o idoso são datadas apenas do século XXI, isto permitiu que as evoluções tecnológicas se desenvolvessem sem que se priorizasse de alguma forma as limitações deste público. É necessário "correr atrás do prejuízo" e buscar alternativas de correção de espaços já edificados, bem como investir na conscientização dos responsáveis pelos projetos de espaços e ambientes. Por maior que seja o incremento tecnológico, não de vislumbra a possibilidade de se evitar o envelhecimento humano, desta forma, não há motivos para se evitar investimentos ergonômicos nesta área.

A Metodologia para Projetos de Construção Centrados no Usuário, proposta por Attaianese e Duca (2012) se mostrou objetiva, no entanto (até a realização do presente estudo), não se encontrou uma publicação sobre a aplicação detalhada das etapas propostas na estrutura de procedimentos. Outro ponto percebido foi que a metodologia disponibilizada pelas autoras não estabelece procedimentos acerca da antropometria e conforto ambiental, assim como aos aspectos psicológicos pertinentes ao público alvo, assuntos esses pelo qual se faz necessário obter informações para a composição da pesquisa, exigindo uma maior sensibilidade e experiência do pesquisador. Para complementar o estudo foi acrescentada a Análise Antropométrica e de Conforto Ambiental, tópicos importantes para se obter parâmetros essenciais a uma pesquisa ligada a Ergonomia, onde foi possível realizar medições e comparativos com normas em vigor.

Como sugestão para desdobramentos da pesquisa, propõe-se a avaliação do restante dos ambientes da instituição analisada, bem como o cotejamento dos resultados com resultados de avaliações de outras instituições, no intuito de verificar níveis de adequação, bem como a assunção de soluções a problemas similares.

\section{Referências bibliográficas}

ANVISA, Agência Nacional de Vigilância Sanitária. Resolução da Diretoria Colegiada (RDC) n²83. Brasília, 2005.

ATTAIANESE, E.; DUCA, G. Human factors and ergonomic principles in building design for life and work activities: an applied methodology. Theoretical Issues in Ergonomics Science. Vol. 13, No. 2, March-April 2012, 187-202.

BOECHAT, N. S. Institucionalização. Arqu. Geriat. Geront., Rio de Janeiro, p. 58-61, maio 1996.

BORN, Tomiko e BOECHAT, Norberto. A Qualidade dos Cuidados ao Idoso Institucionalizado. In: FRETAS, Elizabete, et al. Tratado de Geriatria e Gerontologia. $1^{a}$ ed., Rio de Janeiro: Guanabara Koogan , 2002, v. único, c. 93, p. $768-777$.

CAMARANO, Ana. Os novos idosos brasileiros muito além dos 60 . Ipea. Instituto de pesquisa econômica aplicada. Rio de Janeiro- RJ. 2005.

CALDAS, C. P. Envelhecimento de dependência: responsabilidades e demandas da família. Cad. Saúde Pública. São Paulo, v.19, n.3, p. 733-781, maio 2003.

CHAIMOWICZ, F.; GRECO, D. Dinâmica da Institucionalização de idosos em Belo Horizonte. Rev. Saúde Pública. São Paulo, v.33, n.5, p. 454460, 1999.

Costa, E. F. A., \& Pereira, S. R. M. (2005). Meu corpo está mudando o que fazer? In J. L. Pacheco, J. L. M. Sá, L. Py \& S. N. Goldman (Orgs.),

Tempo rio que arrebata (pp.13-25). Holambra: Setembro. 


\section{$16^{\circ}$ \\ ERGODESIGN USIHC CINAHPA}

CREUTZBERG, Marion; GONÇALVES, Lucia; SOBOTTKA, Emil. Instituição de longa permanência para idosos: a imagem que permanece. Tese de doutorado. Instituto de Geriatria e Gerontologia da Pontifícia Universidade Católica do Rio Grande do Sul (PUC/RS). Florianópolis-SC, 2008.

ESQUENAZI, D.; SILVA, S. R. B.; GUIMARÃES, M. A. M. Aspectos fisiopatológicos do envelhecimento humano e quedas em idosos. Revista HUPE, Rio de Janeiro, 2014; 13 (2) : 11-20.

FLORES, G.C. Eu cuido dela e ela me cuida: um estudo qualitativo sobre o cuidado intergeracional com o idoso [dissertação]. Santa Maria: Universidade Federal de Santa Maria; 2008.

MONT'ALVÅO, Claudia e VILLAROUCO, Vilma. Um novo olhar para o projeto.

Teresópolis-RJ: 2AB, 2011.

PAIVA, Marie. Ergonomia no Ambiente

Construído de Instituições para Idosos- Estudo de Caso em Instituição Brasileira e Portuguesa. Dissertação de Mestrado. Recife- PE. 2012.

PAVARINI, S.C.I. Dependência comportamental na velhice: uma análise do cuidado prestado ao idoso institucionalizado. Tese (Doutorado). Faculdade de Educação da Universidade Estadual de Campinas. Campinas, 1996. 230p.

PEREIRA, Fernando. Considerações sobre o papel da Ergonomia em idosos economicamente ativos. Mestrado em gerontologia. São Paulo- SP. 2007.

RIBAS, V. G., ELY, V. H. M. Parâmetros para moradia da terceira idade. In: II Ergodesign. Anais... Rio de Janeiro: PUC, 2002. $16^{\circ}$ Ergodesign - Congresso Internacional de Ergonomia e Usabilidade de Interfaces Humano Tecnológica: Produto, Informações Ambientes Construídos e Transporte

$16^{\circ}$ USIHC - Congresso Internacional de Ergonomia e Usabilidade de Interfaces Humano Computador

CINAHPA | 2017 - Congresso Internacional de Ambientes Hipermídia para Aprendizagem.

WATANABE, H.A.W., \& GIOVANNI, V.M.D. (2009). Envelhecimento \& Saúde Boletim do Instituto de Saúde Instituições de Longa Permanência para Idosos (ILPI). BIS, Bol. Inst. Saúde, 47, 69-71.

SALDANHA, A.L.; CALDAS C.P.

(Organizadores). Saúde do idoso: a arte de cuidar. 2ed. Rio de Janeiro: Interciência, 2004. 